\title{
Herpes Zoster and Immunogenicity and Safety of Zoster Vaccines in Transplant Patients: A Narrative Review of the Literature
}

\author{
Lei Wang', Erik A. M. Verschuuren², Coretta C. van Leer-Buter ${ }^{3}$, Stephan J. L. Bakker ${ }^{4}$, \\ Anoek A. E. de Joode ${ }^{4}$, Johanna Westra ${ }^{1}$ and Nicolaas A. Bos ${ }^{1 *}$ \\ ${ }^{1}$ Department of Rheumatology and Clinical Immunology, University Medical Center Groningen, University of Groningen, \\ Groningen, Netherlands, ${ }^{2}$ Department of Pulmonary Diseases, University Medical Center Groningen, University of \\ Groningen, Groningen, Netherlands, ${ }^{3}$ Department of Medical Microbiology, Division of Clinical Virology, University Medical \\ Center Groningen, University of Groningen, Groningen, Netherlands, ${ }^{4}$ Department of Internal Medicine, Division of \\ Nephrology, University Medical Center Groningen, University of Groningen, Groningen, Netherlands
}

OPEN ACCESS

Edited by:

Mario (Mago) Clerici,

Università degli Studi di

Milano, Italy

Reviewed by: Ilaria Righi, Fondazione IRCCS $\mathrm{Ca}$ Granda Ospedale Maggiore Policlinico (IRCCS), Italy Egidio Brocca Cofano, University of Pittsburgh, United States

*Correspondence: Nicolaas A. Bos n.a.bos@umcg.nl

Specialty section: This article was submitted

to Viral Immunology, a section of the journal Frontiers in Immunology

Received: 02 May 2018 Accepted: 02 July 2018 Published: 16 July 2018

Citation:

Wang L, Verschuuren EAM, van Leer-Buter CC, Bakker SJL, de Joode AAE, Westra J and Bos NA (2018) Herpes Zoster and Immunogenicity and Safety of Zoster Vaccines in Transplant Patients: A Narrative Review of the Literature.

Front. Immunol. 9:1632. doi: 10.3389/fimmu.2018.01632
This narrative review focuses on the herpes zoster $(\mathrm{HZ})$ and its prevention in transplant patients. Varicella zoster virus (VZV) is highly contagious and distributed worldwide in humans. Primary VZV infection usually causes varicella and then establishes a lifelong latency in dorsal root ganglia. Reactivation of VZV leads to $\mathrm{HZ}$ and related complications such as postherpetic neuralgia. Age and decreased immunity against VZV are important risk factors for developing $\mathrm{HZ}$. Transplant patients are at increased risk for developing $\mathrm{HZ}$ and related complications due to their immunocompromised status and the need for lifetime immunosuppression. Diagnosis of $\mathrm{HZ}$ in transplant patients is often clinically difficult, and VZV-specific antibodies should be determined by serologic testing to document prior exposure to VZV during their pre-transplant evaluation process. Although antiviral agents are available, vaccination should be recommended for preventing $\mathrm{HZ}$ in transplant patients considering their complicated condition and weak organ function. Currently, there are two licensed $\mathrm{HZ}$ vaccines, of which one is a live-attenuated vaccine and the other is a $\mathrm{HZ}$ subunit vaccine. Both vaccines have shown promising safety and efficacy in transplants patients and especially the subunit vaccine could be administered post-transplant since this vaccine does not contain any live virus. Larger studies are needed about safety and immunogenicity of $\mathrm{HZ}$ vaccines in transplant populations, and extra efforts are needed to increase vaccine usage according to guidelines.

Keywords: varicella zoster virus, herpes zoster, postherpetic neuralgia, transplantation immunology, herpes zoster vaccine

\footnotetext{
Abbreviations: ACIP, Advisory Committee on Immunization Practices; AEs, adverse events; CDC, Centers for Disease Control and Prevention; CMI, cell-mediated immunity; CMV, cytomegalovirus; CSF, cerebrospinal fluid; DFA, direct immunofluorescent assay; ELISA, enzyme-linked immunosorbent assays; ESRD, end-stage renal disease; FAMA, fluorescent antibody to membrane antigen; FDA, Food and Drug Administration; gE, glycoprotein E; HCT, hematopoietic cell transplant; HSCT, hematopoietic stem cell transplant; HSV, herpes simplex virus; HZ, herpes zoster; HZ/su, herpes zoster subunit vaccine; IFNs, interferons; IgG, immune globulin G; JAK/STAT, Janus kinase-signal transducer and activator of transcription; JNK, C-Jun N-terminal kinase; LMP, lidocaine-medicated plasters; MMR, measles-mumps-rubella; PHN, postherpetic neuralgia; SOT, solid organ transplant; SPS, Shingles Prevention Study; STAT3, signal transducer and activator of transcription 3; STPS/LTPS, Short-Term and Long-Term Persistence Substudy; TCAs, tricyclic antidepressants; TK, thymidine kinase; VZV, varicella zoster virus; VZIG, varicella-zoster immune globulin.
} 


\section{INTRODUCTION}

Varicella zoster virus (VZV) belongs to the Alphaherpesvirinae subfamily and is a member of the Varicellovirus genus. VZV is highly contagious and distributed worldwide in humans (1). Primary VZV infection usually occurs during childhood and causes varicella (chickenpox). Following infection by contact with aerosolized vesicle fluid or through the respiratory route, VZV first replicates in epithelial cells of the upper respiratory mucosa. A disseminated vesicular rash appears subsequently after an incubation period of approximately 10-21 days. After primary infection, immunity to VZV is established, while the virus travels by retrograde spread along sensory neurons to the trigeminal and dorsal root ganglia establishing a lifelong latency (2). In elderly people or immunocompromised patients, a reduction in the ability of an appropriate immune response could lead to reactivation of VZV from latency allowing the virus to travel antegradely from the sensory ganglia to the skin nerve terminals and spreading to skin epithelial cells leading to the clinical signs of herpes zoster (HZ) (1). Although the symptoms of $\mathrm{HZ}$ normally resolve within $2-4$ weeks, about $10 \%$ of patients develop postherpetic neuralgia (PHN) - the most frequent chronic complication of HZ. PHN is defined as pain persisting more than 3 months after the onset of the rash in the same affected area. It can interfere with the patients' sleep and daily activities, causing a major loss of quality of life (3). In a systematic review including 130 studies conducted in 26 countries, the incidence rate of $\mathrm{HZ}$ was calculated at 3-5 per 1,000 person-years in North America, Europe, and Asia-Pacific, with a notable rise in persons over 50 years of age, reaching 8-12 per 1,000 person-years at age 80 years. The authors also reviewed the risk of developing PHN in patients with $\mathrm{HZ}$ and found it to range between 5 and $30 \%$, with more than $30 \%$ of patients with PHN experiencing persistent pain for more than 1 year (4). Age is therefore an important risk factor for HZ. Several studies suggested increasing trends of $\mathrm{HZ}$ incidence over the past decade, which also lead to an increase in the prevalence of PHN, but the reasons for these trends are currently still unknown (5). Even more severe complications such as disseminated zoster occur mainly in immunocompromised patients. Disseminated HZ is usually characterized by vesicles spreading beyond the distribution of the affected dermatome, with the potential to affect other organs than the skin, potentially leading to pneumonia, encephalitis, and hepatitis with a $5-10 \%$ fatality rate (6).

Primary VZV infection induces both humoral and cellular immune responses. Several studies suggested that humoral immunity appears later and plays a less prominent role in bridling primary VZV infections compared with cellular immunity. This is supported by the fact that children with B cell deficiencies often recover uncomplicated from primary varicella infections, while children with $\mathrm{T}$ cell deficiencies are at high risk of progressive varicella (7). With regard to prevention of VZV reactivation, cell-mediated immunity (CMI) is believed to be more important than antibodies, although the mechanisms of protection are not fully understood. This is in line with the fact that the numbers of $\mathrm{VZV}$-specific $\mathrm{T}$ cells decrease, whereas anti-VZV-immune globulin $\mathrm{G}(\mathrm{IgG})$ titers remain relatively stable over time $(8,9)$. Another study showed that in the first week after HZ rash onset, greater VZV CMI responses correlated with lower severity of disease, while VZV antibody responses did not correlate with severity of HZ or PHN (10). Type I interferons (IFNs) including IFN- $\alpha$ and IFN- $\beta$ dominate the innate defense system against virus infections. During VZV replication in the skin after reactivation, the signal transducer and activator of transcription 3 is activated by VZV in infected cells, thereby suppressing the expression of INF- $\alpha$ and STAT1, whereas surrounding uninfected cells show upregulation of IFNs and STAT1 (2). Besides, type I and type III IFNs can induce the Janus kinase-signal transducer and activator of transcription (JAK/STAT) pathway, which leads to phosphorylation of STAT1 and STAT2 followed by IFN-stimulated genes expression. Verweij et al. demonstrated that VZV was able to inhibit type I IFN-activated signal transduction by degrading IFN regulatory factor 9 and inhibiting STAT2 phosphorylation of the JAK-STAT pathway (11). Due to the lack of robust models for latency, the mechanisms for VZV latency and subsequent reactivation are still being poorly understood. Sadaoka et al. established an in vitro system which recapitulates elements of VZV latency and reactivation in vivo (12). C-Jun N-terminal kinase (JNK) pathway was found to play a critical role in the viral reactivation using this system and pharmacologic blockade of the JNK pathway could inhibit VZV gene expression, lytic replication, and reactivation (13). A better understanding of the mechanisms underlying VZV reactivation and infection, and how the adaptive immune system can effectively protect during this process, is still largely unknown and an important topic for future investigations.

Transplantation is the only curative therapeutic option for terminal organ failure. In recent years, the number of solid organ transplant (SOT) and hematopoietic stem cell transplant (HSCT) recipients is continuously increasing. For example, about 29,000 SOTs in the U.S. and 19,000 HSCTs worldwide are performed annually (14). The development of novel immunosuppressive agents and better diagnosis of graft rejection have dramatically improved survival of transplant patients (15). Transplant patients are, however, at increased risk for developing $\mathrm{HZ}$ and related complications due to the need for lifetime immunosuppression. The type of transplantation, immunosuppression, and antiviral prophylaxis may influence $\mathrm{HZ}$ incidence. According to several trials and retrospective studies published in the last decade, incidence of HZ varied between 3.5 and $9 \%$ in kidney (16-20), 6.9 and $7.2 \%$ in liver $(18,21), 11.6$ and $14.3 \%$ in lung (22-24), and 16.2 and $16.3 \%$ in heart $(18,25)$ transplant recipients (Table 1). Overall, liver transplant recipients have a lower incidence of $\mathrm{HZ}$, possibly due to their relatively resistance to rejection and less requirement of immunosuppression compared with other organ recipients, whereas heart and lung transplants had a high rate of $\mathrm{HZ}$ possibly explained by the high doses of continuous immunosuppression $(18,26)$.

In this article, we have performed a narrative review of the literature in recent years, providing an in-depth analysis of the development of diagnosis, treatment, and prevention of $\mathrm{HZ}$, and retrospected efficacy and safety of the two currently licensed zoster vaccines in immunocompromised adults, with a focus on transplant patients (Figure 1). This paper aims to emphasize 
TABLE 1 | The incidence of herpes zoster $(\mathrm{HZ})$ in transplant patients.

\begin{tabular}{|c|c|c|c|c|c|}
\hline Reference & Type of transplantation & No. of patients & $\begin{array}{c}\text { No. of patients who } \\
\text { developed HZ }\end{array}$ & Crude incidence of $\mathrm{HZ}(\%)$ & $\begin{array}{l}\text { Calculated incidence of } \mathrm{HZ} \\
\text { (cases/1,000 person-years) }\end{array}$ \\
\hline (16) & Kidney & 612 & 37 & 6 & 28 \\
\hline (17) & Kidney & 1,139 & 40 & 3.5 & a \\
\hline \multirow[t]{3}{*}{ (18) } & Kidney & 500 & 45 & 9 & 24.4 \\
\hline & Liver & 461 & 32 & 6.9 & 18.3 \\
\hline & Heart & 80 & 13 & 16.3 & 40 \\
\hline (19) & Kidney & 450 & 29 & 6.4 & 20.6 \\
\hline (20) & Kidney & 444 & 35 & 7.9 & a \\
\hline (21) & Liver & 377 & 27 & 7.2 & 17.83 \\
\hline (22) & Lung & 239 & 29 & 12.1 & 55.1 \\
\hline (23) & Lung & 198 & 23 & 11.6 & a \\
\hline (24) & Lung & 119 & 17 & 14.3 & 38.2 \\
\hline (25) & Heart & 314 & 51 & 16.2 & 31.6 \\
\hline
\end{tabular}

aThe reference did not show this data.
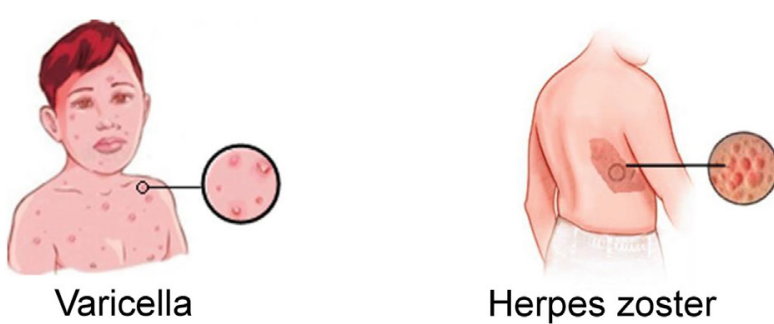

Herpes zoster
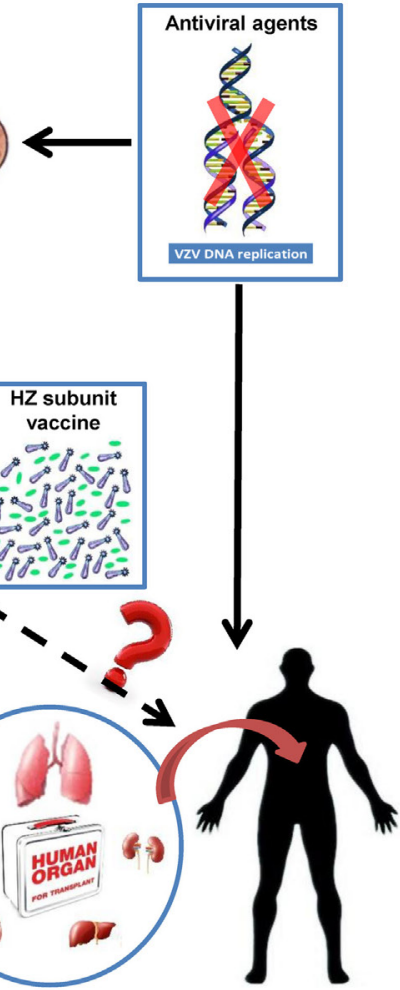

VZV-specific lgG
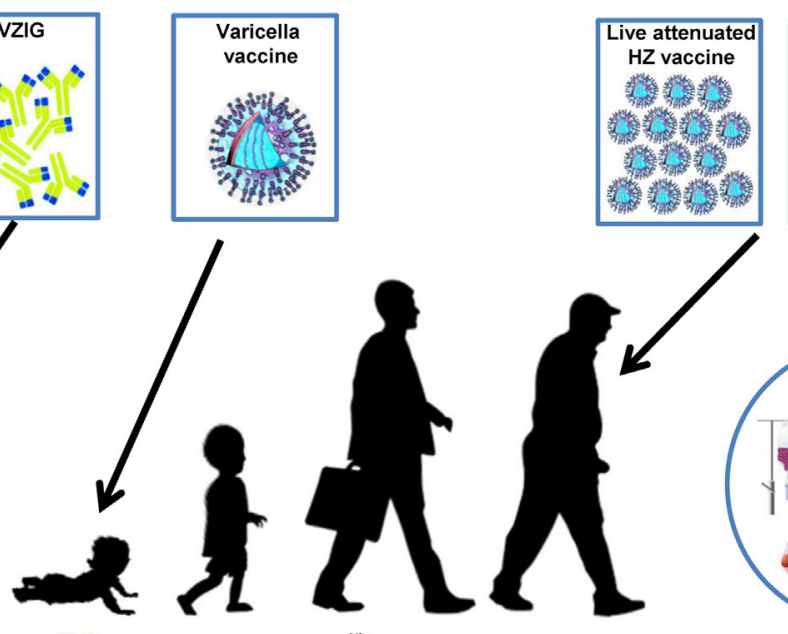

Live attenuated VZV

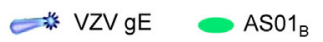

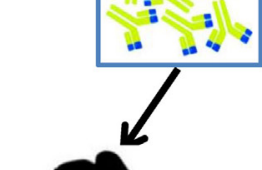

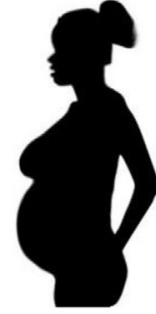

FIGURE 1 | Treatments and prevention of varicella and herpes zoster $(\mathrm{HZ})$.

the dangerous situation of transplant patients facing $\mathrm{HZ}$ and the importance of future clinical trials about safety and efficacy of zoster vaccines in these $\mathrm{HZ}$ high-risk populations.

\section{DIAGNOSIS}

Generally, both primary varicella and HZ have typical clinical presentations that allow for a presumptive clinical diagnosis (26). Primary varicella rash (initially macular, proceeding to fluid-filled vesicles then turning yellow pustular) occurs on the trunk and face, and spreads to involve much of the skin surface (27). The diagnosis of $\mathrm{HZ}$ is based on the characteristic cutaneous eruption, which always presents as erythematous vesicular rash following dermatomal distribution with localized neurological pain (26).

Diagnosis of HZ in transplant patients is clinically often difficult, because $\mathrm{HZ}$ in these patients is more likely to present as atypical mucocutaneous forms that could mimic other cutaneous diseases, such as herpes simplex virus (HSV) infection and drug reactions (28), and may present with multiorgan 
involvement. It rarely develops into invasive complications with delayed or absent rash (26). In case of diagnostic uncertainty, laboratory testing [polymerase chain reaction (PCR)] is suggested and is becoming the standard for confirmation in transplant patients (29).

Viral culture and direct immunofluorescent assay (DFA) are the conventional methods for detecting VZV and have long been considered the gold standards. However, both methods have limitations such as time-consuming, insensitivity, and lack of standardization (30), and DFA also requires great technical expertise and has a high probability to mistakes in specimen collection and storage conditions (31).

Polymerase chain reaction is the most sensitive test for VZV and different PCR-based methods have been introduced to the clinical laboratory, for example, conventional PCR, nested PCR, and real-time PCR (32). PCR can detect VZV virus in vesicle fluid swab, biopsies, cerebrospinal fluid (CSF), intraocular fluids, and blood samples (29). Among these, multiplex real-time PCR assays can simultaneously detect VZV and HSV in CSF and lesion swab specimens in a single test (33). The multiplex assay provides accurate and rapid diagnostic capabilities for the diagnosis and differentiation of HSV and VZV infections with lower costs (34).

In all transplant patients, VZV-specific antibody levels should be determined by serologic testing to document prior exposure to VZV during their pre-transplant evaluation process. The VZV-specific antibodies level can be used for evaluation of the post-transplant risk of seronegative patients developing chickenpox and seropositive patients developing HZ (26). Determination of an increase in anti-VZV IgG and IgM and measurement of VZV DNA in CSF or peripheral blood by PCR are the methods to confirm diagnosis of $\mathrm{HZ}$ sine herpete (defined as dermatomal distribution pain occurring without an antecedent rash) $(28,29)$. Antibody tests for VZV include the fluorescent antibody to membrane antigen (FAMA), enzyme immunoassay, and enzymelinked immunosorbent assays (ELISA). These tests use whole antigens of the virus or antigen extracted from VZV-infected cell cultures, whereas other tests use the external glycoproteins [glycoprotein $\mathrm{E}(\mathrm{gE}), \mathrm{gB}$, and $\mathrm{gH}$ ] as antigens, such as the gpELISA (35). FAMA is highly sensitive and considered the gold standard test for VZV antibodies, but is labor intensive and not automated (36). ELISA is widely used because of its simplicity and the possibility of automation, but still lacks sufficient sensitivity of detecting vaccine seroconversion (37). Combination of serology testing and real-time PCR on paired serum and CSF/ intraocular fluid can be used for diagnosing $\mathrm{HZ}$ with cerebral and ocular complications (38). It is important to develop new precise assays because false-negative and false-positive results due to limitations of serologic testing may lead to unnecessary vaccinations or therapy (35). Even more important is the limitation that antibody titers do not necessarily correlate with protection. It is unknown whether high antibody titers are correct correlates of VZV protection or only a measure of past infection. Seemingly protective antibody titer in a whole virus ELISA may not correlate with protective levels of antibodies directed against membrane antigens (39). Development of methods to determine potential HZ-predisposing VZV-specific cellular adaptive immunity could be promising for the future, because VZV-specific antibodies only have an apparent limited protective effect (24).

\section{TREATMENT}

\section{Herpes Zoster}

The primary goals for the treatment of $\mathrm{HZ}$ by taking antiviral agents are to control the replication of VZV in infected cells and to soothe and protect the infected skin. Lowering the chance of accompanying complications is also a major treatment goal in transplant patients. It is recommended to initiate administration of antivirals in patients with $\mathrm{HZ}$ within $72 \mathrm{~h}$ after cutaneous symptoms onset, or at a later time. Administration as early as possible can decrease the intensity and duration of zosterassociated pain, prevent dissemination and fulminant visceral involvement, accelerate the healing of skin lesions, and improve the affected patients' quality of life. Antiviral agents can still be administered in certain patients who present $>72 \mathrm{~h}$ after the onset of skin symptoms. These patients include elderly patients over 60 years of age with severe pain and HZ in large affected skin areas, patients with persistent new vesicle formation, or immunocompromised patients, and in those with complicated HZ (28). Antiviral therapy can be stopped when no more new vesicles appear. If vesicle formation sustains during treatment over 7 days, the diagnosis should be re-evaluated, and drug resistance may be a problem (40).

The synthetic nucleoside analog of guanine acyclovir and its prodrug valacyclovir, penciclovir's prodrug famciclovir, and the thymidine analog brivudin are the most widely used drugs for the $\mathrm{HZ}$ antiviral treatment (1). When choosing an antiviral drug, all possible factors influencing efficacy should be considered, including routes of administration, dosage frequency, costs, complications contraindications, and drug interactions (40).

\section{Acyclovir}

Acyclovir was the first drug discovered that had antiviral activity against herpes virus and is very safe and well tolerated (41). HZ in immunocompetent patients can be treated orally, but due to the poor oral bioavailability (15-30\%) of acyclovir, other simpler dosing and better pharmacokinetic antiviral drugs (valacyclovir or famciclovir) are preferred $(1,42)$. Intravenous acyclovir with $500 \mathrm{mg} / \mathrm{m}^{2}$ every $8 \mathrm{~h}$ is the initial therapy of choice for a varicellalike rash in SCT recipients. When the infection is controlled, oral antiviral medication is an option for the remainder of the treatment (43).

\section{Valacyclovir}

Valacyclovir is a prodrug of acyclovir with three to five times higher oral bioavailability than acyclovir (44), and it was approved for use as an additional treatment for herpes virus infections in the USA in 1995 (45). The convenient dosing schedule (1,000 mg three times daily) and quicker cessation of pain makes valacyclovir more efficacious than acyclovir in treating acute HZ (46).

\section{Famciclovir}

Famciclovir is a well-absorbed (bioavailability 77\%) first-line option for the treatment of $\mathrm{HZ}$ and used for treating $\mathrm{HZ}$ in 
immunocompetent adults and immunosuppressed patients older than 25 years, but not approved in childhood and adolescence (1). In a study with 148 patients who were immunocompromised following bone marrow or solid organ transplantation or oncology treatment, the efficacy and safety of famciclovir was evaluated. The study showed that oral famciclovir is convenient, effective, and well tolerated for immunocompromised patients with HZ (47).

\section{Brivudin}

Brivudin is a thymidine nucleoside analog with stronger antiviral effect against VZV than reference compounds such as acyclovir by blocking the action of DNA polymerases. Oral brivudin (125 mg once daily) is licensed for the treatment of HZ in several countries of the European Union (48). In a double-blind randomized multicenter study, 48 immunocompromised patients with a $\mathrm{HZ}$ rash less than $72 \mathrm{~h}$ in duration received brivudin or intravenous acyclovir treatment. No significant difference was seen regarding cutaneous or visceral dissemination compared between the two therapies (49). Brivudin is not available in all countries and not approved for antiviral therapy in children and adolescents due to lacking of studies about safety profile $(1,40)$.

\section{Antiviral Agents Used to Treat Herpes Viruses Other Than VZV and Co-Infections}

Ganciclovir and its valyl-ester valganciclovir, and foscarnet are primarily used to treat cytomegalovirus (CMV) infections (50). Both agents are nevertheless active against VZV and may be used to treat double infections or to suppress reactivations (51).

Although foscarnet dosing to treat VZV has not been studied extensively, doses required to treat CMV infections have been shown to treat VZV successfully. Foscarnet, however, is considerably more toxic than acyclovir. It is only recommended for the treatment of CMV co-infections, or when antiviral resistance is suspected (52).

Likewise, ganciclovir and valganciclovir are largely used for the treatment of CMV infections, but both agents possess excellent activity against VZV in doses used to treat CMV infections (51). Its toxicity especially to bone marrow restricts its use to prophylaxis and treatment of CMV co-infections $(53,54)$.

\section{Postherpetic Neuralgia}

Postherpetic neuralgia tends to be underdiagnosed and inadequately managed, so treatments of PHN are palliative and shortening of duration and severity of pain is the main goal of PHN management $(55,56)$. According to the guidelines (2010) issued by the European Federation of Neurological Societies, tricyclic antidepressants (TCAs), antiepileptics (gabapentin/pregabalin), and topical lidocaine plaster (5\%) are recommended as first-line treatment in PHN (57).

\section{Tricyclic Antidepressants}

Tricyclic antidepressants, including two classes-the secondary amines (nortriptyline and desipramine) and the tertiary amines (amitriptyline and imipramine) - have been commonly used for the treatment of PHN from the early 1980s (55). TCAs can block voltage-dependent sodium channels and $\alpha$-adrenergic receptors and also inhibit the reuptake of monoaminergic transmitters which can enhance the effects of biogenic amines in modulating descending pain pathways (58). Clinical experience showed TCAs to be effective in the control of PHN and amitriptyline is the most commonly used TCAs which can improve patients sleep more due to its sedating property. However, TCAs are often poorly tolerated with a relatively slow onset of action and associated with systemic adverse events (AEs) such as dry mouth, constipation, serotonin syndrome, cardiotoxicities, and anticholinergic effects. TCAs side effects are common in the mostly elderly population afflicted with PHN thus alternative treatments may be considered (3).

\section{Antiepileptics}

Oral antiepileptics gabapentin and pregabalin can block voltagesensitive calcium channel, decrease the release of several neurotransmitters, and inhibit central pain pathways. In clinical trials, gabapentin and pregabalin significantly reduced PHN-related pain and improved sleep quality more than placebo $(59,60)$. Gabapentin may be superior to other formulations in terms of compliance and safety, while pregabalin was associated with better health outcomes and cost-effectiveness $(60,61)$. The most common side effects of gabapentin and pregabalin are dizziness, somnolence, and peripheral edema $(62,63)$. These AEs could limit their use in some patients.

\section{Lidocaine Plasters (5\%)}

Lidocaine-medicated plasters (LMP) were approved to use in the treatment of PHN by the Food and Drug Administration (FDA) in 1999 and have been licensed in several European, Latin American, and the Middle East countries since then (64). As a topical analgesic, 5\% LMP can deliver the drug directly to the site of pain and provides local pain relief through localized analgesia, without inducing anesthesia or numbness (64). In a systematic review including 20 unique studies, 5\% LMP showed similar effects on pain relief compared with gabapentin and was more effective than placebo, capsaicin, and pregabalin (change in pain from baseline) (65). 5\% LMP is more cost-effective than pregabalin in a UK setting (66) and demonstrated good short- and long-term tolerability with a minimal risk for systemic adverse drug reactions (67).

\section{Polypharmacy}

Because monotherapy may not be sufficient of modifying all of the complex pain mechanisms that underlie PHN, combination therapies are frequently applied and five or more drugs on average are taken by a typical PHN patient (56). Due to the low tendency of gabapertinoids and topical analgesics for interactions with other drugs, they have become the most attractive agents for combination therapies (55). A randomized, open-label, multicenter, non-inferiority study indicated that combination of pregabalin and 5\% LMP provided additional efficacy for pain relief in PHN in patients unresponsive to either monotherapy (68).

Concerning transplant patients, their complicated condition and weak organ function such as renal impairment, could affect drug metabolism and tolerability (69). In the setting of polypharmacy, it would be more difficult to choose and dosage would also 
change according to every patient's situation, while side effects of different drugs should also be considered. Besides, once patients develop PHN after HZ, the condition does not usually adequately respond to treatment (70).

\section{PREVENTION/PROPHYLAXIS}

\section{Vaccination}

Current treatment strategies for $\mathrm{HZ}$ and $\mathrm{PHN}$ are only partially effective, so reducing the burden of $\mathrm{HZ}$ by prophylactic vaccination may be a proactive strategy (71).

\section{Live-Attenuated Zostavax ${ }^{\circledR}$ (Merck, USA)}

In 2006, the FDA approved the 1-dose live-attenuated $H Z$ vaccine Zostavax $^{\circledR}$ for use in individuals 60 years of age and older and expanded the use of Zostavax ${ }^{\circledR}$ among adults aged 50 through 59 years in March 2011 (72). In 2017, the Advisory Committee on Immunization Practices (ACIP) reviewed their guidelines and Zostavax ${ }^{\circledR}$ remained as a recommended vaccine for immunocompetent adults aged over 60 years to prevent HZ (73).

Zostavax $^{\circledR}$ contains at least a 14 times higher titer of the same live-attenuated Oka/Merck strain used in the varicella vaccine $\left(\right.$ Varivax $^{\circledR}$, a live-attenuated varicella vaccine for the prevention of chickenpox) and is therefore only recommended for VZV seropositive people (74). Several studies have shown the efficacy of Zostavax ${ }^{\circledR}$ in HZ and PHN prevention. The Shingles Prevention Study (SPS) was a randomized, double-blind, placebo-controlled study that enrolled 38,546 adults over the age of 60 years and showed that Zostavax ${ }^{\circledR}$, respectively, reduced the incidence of HZ and PHN by 51.3 and $66.5 \%$ in 4 years of postvaccination follow-up. However, the efficacy against $\mathrm{HZ}$ incidence decreased with age $(37.6 \%$ among subjects $\geq 70$ years old and $63.9 \%$ among younger subjects) $(75,76)$. To further assess the persistence of vaccine efficacy, the Short-Term and Long-Term Persistence Substudy were undertaken following SPS. The STPS re-enrolled 14,270 SPS vaccine and placebo recipients, and after 5 years, vaccine efficacies for $\mathrm{HZ}$ burden of illness, the incidence of $\mathrm{PHN}$, and the incidence of $\mathrm{HZ}$ decreased from 61.1 to $50.1 \%, 66.5$ to $60.1 \%$, and 51.3 to $39.6 \%$, respectively (77). In the LTPS, vaccine efficacy declined for all these three outcome measures from 7 to 11 years postvaccination (78). To reverse this decline in efficacy, a booster dose of Zostavax $^{\circledR}$ could be a potential solution. HZ vaccine was given as a second dose to 200 subjects over the age of 70 years who had received one dose Zostavax ${ }^{\circledR} \geq 10$ years before in a study, and the VZV-specific cellular and humoral responses to this booster dose were compared with older and younger vaccinee. This study showed that while VZV antibody levels were similar in all age groups, VZV-specific CMI was significantly higher in the booster-dose group. The authors suggested that more clinical trials of appropriate age of vaccine administration as well as the potential of booster dose would be required (79).

Because post-transplantation, humoral and cellular responses to vaccines are suboptimal, it is important to immunize patients while they are awaiting transplantation. This should optimally be part of a comprehensive pre-transplant evaluation and preparation (80). Zostavax ${ }^{\circledR}$ is contraindicated after transplantation, because of the increased risk for live vaccine-induced infections, caused by the altered immunocompetence. According to the 2008 ACIP guideline, zoster vaccine should be administered at least 14 days before initiation of immunosuppressive therapy. Zoster vaccine is recommended in HSCT candidates over 4 weeks before transplantation but contraindicated after HSCT due to limited experience of HSCT recipients with life VZVcontaining vaccines (14). Vaccination may be considered after assessing of the immune status of the recipient on a case-by-case basis and only administered at least 24 months after HSCT (81).

A study retrospectively assessed the use of Zostavax ${ }^{\circledR}$ in 62 patients with hematologic malignancy. Among them, 31 patients received hematopoietic cell transplant (HCT), and the median times to vaccination post-transplant were 482 days (26 patients received autologous HCT) and 1,323 days (5 patients received allogeneic HCT). There were no documented AEs associated with administration of Zostavax ${ }^{\circledR}$ among all the patients. One patient developed HZ 3 weeks after vaccination, but they could not establish whether this was caused by wild-type VZV or the Oka/Merck strain because genotyping data were not included in this study (82). In another study, a single dose of Zostavax ${ }^{\circledR}$ was given to 110 adult autologous and allogeneic HSCT recipients about 2 years post-transplantation. Two patients developed a skin rash with unclear reason after vaccination and $98.2 \%$ of vaccine recipients had no AEs within a median 9.5 months follow-up period (83). In a retrospective study about the safety of measles-mumps-rubella (MMR) vaccine and Zostavax ${ }^{\circledR}$ in multiple myeloma patients about 24 months after autologous HCT, 70 patients on maintenance lenalidomide received one dose $\mathrm{HZ}$ vaccine (69 patients also received MMR vaccine). No rash or other AEs related to the vaccines were identified and one patient with previous PHN history experienced worsening pain without rash while the reason leading to this situation was unknown (84). Miller et al. conducted a randomized, placebocontrolled study, which enrolled 34 participants with end-stage renal disease awaiting renal transplantation ( 26 subjects received one dose Zostavax ${ }^{\circledR}$ and 8 received placebo). From 30 to 235 days after vaccination, 14 subjects underwent transplantation and 12 of them received zoster vaccine. There were no zoster rashes or reactogenicity events associated with vaccine that happened to subjects (85). Though limitations exists, including small sample size and lacking of longer follow-up, these studies show a potential benefit of $\mathrm{HZ}$ vaccine in transplant patients before and after the transplantation with a good safety profile. Larger, controlled studies are needed to further explore the safety and efficacy of Zostavax $^{\circledR}$ in HCT and SOT population $(82,83)$.

\section{The HZ Subunit Vaccine (HZ/su, Shingrix $\left.{ }^{\circledR}\right)$}

Subunit vaccines can provoke a strong immune response, while being a safe vaccine for transplant patients, because they avoid the risk of disease caused by replication of the vaccine virus (86).

A new recombinant subunit vaccine (Shingrix ${ }^{\circledR}$ ) containing VZV gE and the AS01B adjuvant system was tested by GlaxoSmithKline in 2015. In a phase III randomized study including 15,411 participants ( $\geq 50$ years of age) from 18 countries, two doses of the HZ/su administered 2 months apart had a vaccine efficacy of $97.2 \%$ and significantly reduced the $\mathrm{HZ}$ 
in adults 50 years of age or older (87). HZ/su also had a vaccine efficacy of $89.8 \%$ in adults over 70 years old and showed no decline in efficacy with age (88). Besides, a follow-up, multicenter, single group trial conducted in the Czech Republic, the Netherlands, Germany, and Sweden indicated that both gE-specific cellular and humoral immune responses decreased over time but remained substantially above prevaccination levels for up to 6 years in healthy older adults who had received two doses of $\mathrm{HZ} / \mathrm{su}$. HZ/su seems to have the potential to provide long-term protection against HZ in older adults (89). Solicited reports of injection-site and systemic reactions such as fatigue and myalgia were more among $\mathrm{HZ} / \mathrm{su}$ than placebo, but the reactions were generally mild-to-moderate in intensity and serious AEs and deaths were similar in the vaccine and placebo groups (87-89). A cost-effectiveness analysis using Markov decision model compared HZ subunit vaccine, Zostavax ${ }^{\circledR}$ or no vaccination in immunocompetent adults $\geq 60$ years old. The schedule with two doses HZ/su (at a price of $\$ 280$ per series) was found to be more effective and at lower costs than Zostavax ${ }^{\circledR}$ (90). Shingrix ${ }^{\circledR}$ was approved by FDA for the prevention of $\mathrm{HZ}$ in adults older than 50 years old and recommended by ACIP for use in immunocompetent adults aged $\geq 50$ years in October 2017. ACIP also made the comment that Shingrix ${ }^{\circledR}$ is recommended for immunocompetent adults who received live-attenuated $\mathrm{HZ}$ vaccine before and Shingrix ${ }^{\circledR}$ is preferred over Zostavax ${ }^{\circledR}$ for the prevention of $\mathrm{HZ}$ and related complications (73).

With regard to transplant patients, so far there is only one published study about the $\mathrm{HZ} / \mathrm{su}$ in autologous $\mathrm{HCT}$ recipients. In this phase I/II, randomized, observer-blind, placebocontrolled study, three-dose regimen was found well tolerated and immunogenic in adults who had undergone autologous HSCT 50-70 days earlier. Both humoral and cellular immune responses were strong and persisted for up to 1 year postvaccination. Although with annotated limitations of small numbers of subjects and requirements for additional follow-up, the result shows a promising prospect for immunization of transplant patients (91). More studies especially phase III follow-up trials are still needed. Finally, a phase III trial assessing the efficacy of $\mathrm{HZ} / \mathrm{su}$ in autologous stem cell transplant patient is under way and phase I/II trials in SOTs are in progress (92).

\section{Antiviral Agents}

Long-term acyclovir/valacyclovir prophylaxis to prevent recurrent VZV infection is routinely recommended by the 2009 International Guidelines for the first year after HCT for VZV-seropositive allogeneic (should generally be offered) and autologous (optional) HCT recipients (93). In a systematic review including six observational studies involving 3,420 HSCT recipients, the optimal duration of antiviral prophylaxis (acyclovir, valacyclovir, and famciclovir) for preventing $\mathrm{HZ}$ was analyzed. It was found that antiviral prophylaxis may significantly decrease the reactivation of VZV in HSCT recipients and patients taken antiviral prophylaxis at least 1 year compared with less than 1 year showed lower incidence of HZ (2.1 and 15.4\%, respectively) (94). In SOT recipients, prophylaxis such as acyclovir has not been systematically studied (26). Koo et al. reviewed the medical files of 314 heart transplant recipients from 1995 to 2010.134 patients received ganciclovir/valganciclovir-based CMV prophylaxis for a median of 143 days post-transplantation. The majority of patients develop VZV infection during the first post-transplant year and the risk of $\mathrm{HZ}$ decreased with ganciclovir or valganciclovir prophylaxis (25). In another study including 444 adult kidney transplants, administering anti-CMV prophylaxis (ganciclovir/ valganciclovir) for 3-6 months after transplantation reduced the risk of $\mathrm{HZ}$ and no patients developed $\mathrm{HZ}$ during CMV antiviral prophylaxis (20). Although antiviral prophylaxis is effective for preventing $\mathrm{HZ}$, the risk of VZV reactivation is still much higher in transplant patients than the general population $(20,95,96)$. It is also difficult to completely prevent the development of HZ after the discontinuation of prophylaxis. Once prophylaxis was discontinued, the cumulative risk for developing VZV disease remained high $(95,97)$. Besides, the emergence of resistant VZV strains due to long-term prophylaxis is also a potential risk that cannot be neglected despite no antiviral agent-resistant VZV was observed so far (97).

\section{Post-Exposure Prophylaxis (Seronegative Patients Only)}

Varicella-zoster immune globulin (VZIG) is a purified human IgG with high titers of antibodies to VZV and used to provide passive immunization for seronegative patients exposed to VZV (98). In December 2012, FDA approved a VZV immune globulin preparation VariZIG (Cangene Corp., Winnipeg, MB, Canada) for use in the U.S. as a post-exposure prophylaxis of varicella (99). In July 2013, the Centers for Disease Control and Prevention (CDC) updated recommendations for use of VariZIG. The CDC recommended that patients without evidence of immunity to varicella who are at high risk for severe varicella and complications should receive VariZIG as soon as possible after exposure to varicella-zoster virus and within 10 days. Patient groups recommended by CDC to receive VariZIG include the following:

(1) immunocompromised patients without evidence of immunity;

(2) newborn infants whose mothers have signs and symptoms of varicella around the time of delivery (i.e., 5 days before to 2 days after);

(3) hospitalized premature infants born at $\geq 28$ weeks of gestation whose mothers do not have evidence of immunity to varicella;

(4) hospitalized premature infants born at $<28$ weeks of gestation or who weigh $\leq 1,000 \mathrm{~g}$ at birth, regardless of their mothers' evidence of immunity to varicella; and

(5) pregnant women without evidence of immunity (99).

So far, there is a lack of evidence in prior studies about the use of VZIG to prevent severe varicella, $\mathrm{HZ}$, and relevant complications in SOT patients, and most reports about successful use of VZIG are in pregnant women and infants. In a study form Denmark involving 104 pregnant women who received VZIG from December 2005 to March 2015, only five (6\%) women developed varicella during VZIG treatment and VZIG seems effective in preventing varicella and zoster (100). In a retrospective record review of 812 adult renal transplant recipients, performed from 1995 until 2004 
TABLE 2 | Herpes zoster $(H Z)$ vaccine usage in transplant patients.

\begin{tabular}{|c|c|c|c|c|c|}
\hline Reference & Vaccine & $\begin{array}{l}\text { Number and type } \\
\text { of patients }\end{array}$ & $\begin{array}{l}\text { Median time to vaccination } \\
\text { pre/post-transplantation }\end{array}$ & $\mathrm{HZ}$ after vaccination & Adverse events (AEs) \\
\hline (82) & Zostavax ${ }^{\circledR}$ & $\begin{array}{l}62 \text { patients with hematologic } \\
\text { malignancy: among them } 26 \\
\text { (41.9\%) underwent autologous } \\
\text { hematopoietic cell transplant } \\
(\mathrm{HCT}) ; 5(8.1 \%) \text { underwent } \\
\text { allogeneic HCT; } 31 \text { (50\%) } \\
\text { without HCT }\end{array}$ & $\begin{array}{l}482 \text { days after autologous HCT; } \\
\text { 1,323 days after allogeneic HCT }\end{array}$ & $\begin{array}{l}\text { One patient underwent autologous } \\
\mathrm{HCT} \text { developed } \mathrm{HZ} 3 \text { weeks after } \\
\text { vaccination and was treated with } \\
10 \text { days of high dose acyclovir }\end{array}$ & No documented AEs \\
\hline (83) & Zostavax $^{\circledR}$ & $\begin{array}{l}52 \text { patients underwent autologous } \\
\text { hematopoietic stem cell transplant } \\
\text { (HSCT); } 58 \text { patients underwent } \\
\text { allogeneic HSCT }\end{array}$ & 27 months after HSCT & $\begin{array}{l}\text { One patient underwent } \\
\text { autologous HSCT developed a } \\
\text { skin rash } 10 \text { days after vaccination. } \\
\text { One patient underwent allogeneic } \\
\text { HSCT developed a vesicular skin } \\
\text { rash } 24 \text { days after vaccination } \\
\text { and was treated with valacyclovir }\end{array}$ & $\begin{array}{l}108(98.2 \%) \text { patients had } \\
\text { no clinically apparent AEs }\end{array}$ \\
\hline (84) & Zostavax $^{\circledR}$ & $\begin{array}{l}70 \text { multiple myeloma patients on } \\
\text { maintenance lenalidomide with } \\
\text { autologous HCT: among them } 69 \\
\text { patients also received measles- } \\
\text { mumps-rubella vaccination }\end{array}$ & 25 months after HCT & $\begin{array}{l}\text { Two patients developed a non- } \\
\text { specific rash requiring no therapy } \\
\text { and resolved by themselves }\end{array}$ & $\begin{array}{l}\text { Upper respiratory tract infection } \\
\text { is the most common } \mathrm{AE} \\
\text { (10/70 patients) } \\
\text { One patient with pre-existing } \\
\text { postherpetic neuralgia ( } \mathrm{PHN}) \\
\text { experiencing worsening of } \mathrm{PHN} \\
\text { without development of a rash }\end{array}$ \\
\hline (85) & Zostavax $^{\circledR}$ & $\begin{array}{l}26 \text { patients with end-stage } \\
\text { renal disease awaiting renal } \\
\text { transplantation: among them } \\
12(46 \%) \text { received transplantation }\end{array}$ & $\begin{array}{l}\text { From } 30 \text { to } 235 \text { days before } \\
\text { transplantation }\end{array}$ & No zoster rashes happened & $\begin{array}{l}\text { Local reactogenicity symptoms } \\
\text { occurred in } 9 \text { subjects ( } 35 \%) \text {. } \\
\text { No AEs associated with vaccine }\end{array}$ \\
\hline (91) & $\begin{array}{l}\text { Recombinant } \\
\mathrm{HZ} \text { vaccine }\end{array}$ & $\begin{array}{l}120 \text { patients underwent } \\
\text { autologous HCT: } 30 \text { patients } \\
\text { received } 3 \text { doses of gE/ASO1 } ; 29 \\
\text { patients received } 3 \text { doses of } \\
\text { gE/ASO1E; } 31 \text { patients received } \\
2 \text { doses of gE/ASO1B; } 30 \text { patients } \\
\text { received } 3 \text { doses of saline }\end{array}$ & $\begin{array}{l}\text { Patients underwent } \mathrm{HCT} \\
\text { in the previous } 50-70 \text { days }\end{array}$ & $\begin{array}{l}\text { Two patients in the } 3 \text { doses of } \\
\text { gE/AS01E and two patients in } \\
\text { the saline group developed } \mathrm{HZ}\end{array}$ & $\begin{array}{l}\text { Most subjects experienced } \\
\text { solicited local and general } \\
\text { reactions of mild or moderate } \\
\text { intensity } \\
\text { One patient in the } 2 \text { doses of } \\
\text { gE/AS01B group had serious } \\
\mathrm{AE} \text { (pneumonia) and was } \\
\text { considered vaccine related }\end{array}$ \\
\hline
\end{tabular}

in a single center, eight patients developed varicella infection and six of these patients received VZIG with acyclovir. There was no significant impact of the use of VZIG on the clinical spectrum of the disease and the authors concluded that passive immunization with VZIG is useless once clinical varicella has already established, a finding that is in agreement with other studies (101). Due to the high cost and short supply of VZIG in some, alternative approach of prophylaxis using antiviral agents or vaccination against VZV is needed $(43,102,103)$.

\section{PROSPECT}

Despite great advances in transplantation in recent decades, infection still is a major cause of morbidity and mortality among transplant recipients. Transplant patients are at high risk for developing $\mathrm{HZ}$ and accompanying complication such as PHN and disseminated cutaneous disease $(14,18,104)$. In addition, treatments for transplant patients are more difficult because of their complicated conditions and reduced organ function (69). Regular screening to evaluate each patient's humoral and cellular immunity against VZV and ensuring early recognition and preventing $\mathrm{HZ}$ by vaccination may be a proactive strategy. Currently, there are two licensed $\mathrm{HZ}$ vaccine, the live-attenuated vaccine Zostavax ${ }^{\circledR}$ and the recombinant subunit vaccine Shingrix $^{\circledR}$. For immunocompetent older people within the recommend immunization age, vaccination rate is still low in the U.S. In a retrospective observational study conducted in $2015,6,746,476$ U.S. adults aged $\geq 60$ years during 2007-2013 and 6,770,294 adults aged 50-59 years during 2011-2013 were identified as vaccinated. This study found that $19.5 \%$ of adults aged $\geq 60$ years received an $\mathrm{HZ}$ vaccine, which is lower than the $30 \%$ target of Healthy People 2020 (including objectives designed to serve as this decade framework for improving the health of all people in the U.S.) (105). For transplant patients, $\mathrm{HZ}$ vaccine usage after transplantation is still contraindicated in this population due to its live-attenuated characteristic. Pre-transplantation immunization is considered a relevant alternative, but efficacy of protection after transplantation still needs to be established. Both HZ vaccines have been tested in autologous HCT recipients and showed promising safety and efficacy (Table 2). Shingrix ${ }^{\circledR}$ is a candidate for a post-transplant vaccine as it does not contain any live virus. Larger, prospective, controlled studies are warranted to further determine the safety and efficacy of Zostavax ${ }^{\circledR}$ and Shingrix ${ }^{\circledR}$ in transplant 
populations, and extra efforts are needed to increase vaccine usage according to guidelines.

\section{AUTHOR CONTRIBUTIONS}

LW, JW, and NB contributed to the conception, design, and writing this article. $\mathrm{EV}, \mathrm{CL}-\mathrm{B}, \mathrm{SB}$, and $\mathrm{AJ}$ contributed to the revision of this article.

\section{REFERENCES}

1. Sauerbrei A. Diagnosis, antiviral therapy, and prophylaxis of varicellazoster virus infections. Eur J Clin Microbiol Infect Dis (2016) 35:723-34. doi:10.1007/s10096-016-2605-0

2. Zerboni L, Sen N, Oliver SL, Arvin AM. Molecular mechanisms of varicella zoster virus pathogenesis. Nat Rev Microbiol (2014) 12:197-210. doi: $10.1038 /$ nrmicro3215

3. Nalamachu S, Morley-Forster P. Diagnosing and managing postherpetic neuralgia. Drugs Aging (2012) 29:863-9. doi:10.1007/s40266-012-0014-3

4. Kawai K, Gebremeskel BG, Acosta CJ. Systematic review of incidence and complications of herpes zoster: towards a global perspective. BMJ Open (2014) 4:004833. doi:10.1136/bmjopen-2014-004833

5. Esposito S, Principi N. Herpes zoster prevention: a difficult problem to solve. Vaccine (2017). doi:10.1016/j.vaccine.2017.07.099

6. Johnson RW, Alvarez-Pasquin M, Bijl M, Franco E, Gaillat J, Clara JG, et al. Herpes zoster epidemiology, management, and disease and economic burden in Europe: a multidisciplinary perspective. Ther Adv Vaccines (2015) 3:109-20. doi:10.1177/2051013615599151

7. Haberthur K, Engelmann F, Park B, Barron A, Legasse A, Dewane J, et al. CD4 $\mathrm{T}$ cell immunity is critical for the control of Simian varicella virus infection in a nonhuman primate model of VZV infection. PLoS Pathog (2011) 7:e1002367. doi:10.1371/journal.ppat.1002367

8. Levin MJ, Smith JG, Kaufhold RM, Barber D, Hayward AR, Chan CY, et al. Decline in varicella-zoster virus (VZV)-specific cell-mediated immunity with increasing age and boosting with a high-dose VZV vaccine. J Infect Dis (2003) 188:1336-44. doi:10.1086/379048

9. Schub D, Janssen E, Leyking S, Sester U, Assmann G, Hennes P, et al. Altered phenotype and functionality of varicella zoster virus-specific cellular immunity in individuals with active infection. J Infect Dis (2015) 211:600-12. doi:10.1093/infdis/jiu500

10. Weinberg A, Zhang JH, Oxman MN, Johnson GR, Hayward AR, Caulfield MJ, et al. Varicella-zoster virus-specific immune responses to herpes zoster in elderly participants in a trial of a clinically effective zoster vaccine. J Infect Dis (2009) 200:1068-77. doi:10.1086/605611

11. Verweij MC, Wellish M, Whitmer T, Malouli D, Lapel M, Jonjić S, et al. Varicella viruses inhibit interferon-stimulated JAK-STAT signaling through multiple mechanisms. PLoS Pathog (2015) 11:e1004901. doi:10.1371/ journal.ppat.1004901

12. Sadaoka T, Depledge DP, Rajbhandari L, Venkatesan A, Breuer J, Cohen JI. In vitro system using human neurons demonstrates that varicella-zoster vaccine virus is impaired for reactivation, but not latency. Proc Natl Acad Sci U S A (2016) 113:2403. doi:10.1073/pnas.1522575113

13. Kurapati S, Sadaoka T, Rajbhandari L, Jagdish B, Shukla P, Ali MA, et al. Role of the JNK pathway in varicella-zoster virus lytic infection and reactivation. J Virol (2017) 91:e00640-17. doi:10.1128/JVI.00640-17

14. L'Huillier AG, Kumar D. Immunizations in solid organ and hematopoeitic stem cell transplant patients: a comprehensive review. Hum Vaccin Immunother (2015) 11:2852-63. doi:10.1080/21645515.2015.1078043

15. Netchiporouk E, Tchervenkov J, Paraskevas S, Sasseville D, Billick R. Evaluation of varicella zoster virus infection morbidity and mortality in pancreas and kidney-pancreas transplant recipients. Transplant Proc (2013) 45:701-4. doi:10.1016/j.transproceed.2012.10.022

16. Arness T, Pedersen R, Dierkhising R, Kremers W, Patel R. Varicella zoster virus-associated disease in adult kidney transplant recipients: incidence and risk-factor analysis. Transpl Infect Dis (2008) 10:260-8. doi:10.1111/j. 1399-3062.2007.00289.x

\section{ACKNOWLEDGMENTS}

All the authors thank their respective Institutes and Universities.

\section{FUNDING}

This work was financially supported by the Chinese Scholarship Council.

17. Mustapic Z, Basic-Jukic N, Kes P, Lovcic V, Bubic-Filipi L, Mokos I et al. Varicella zoster infection in renal transplant recipients: prevalence, complications and outcome. Kidney Blood Press Res (2011) 34:382-6. doi: $10.1159 / 000328730$

18. Pergam SA, Forsberg CW, Boeckh MJ, Maynard C, Limaye AP, Wald A, et al Herpes zoster incidence in a multicenter cohort of solid organ transplant recipients. Transpl Infect Dis (2011) 13:15-23. doi:10.1111/j.1399-3062. 2010.00547.x

19. Pavlopoulou ID, Poulopoulou S, Melexopoulou C, Papazaharia I, Zavos G, Boletis IN. Incidence and risk factors of herpes zoster among adult renal transplant recipients receiving universal antiviral prophylaxis. BMC Infect Dis (2015) 15:285. doi:10.1186/s12879-015-1038-1

20. Fernández-Ruiz M, Origüen J, Lora D, López-Medrano F, González E, Polanco N, et al. Herpes zoster in kidney transplant recipients: protective effect of anti-cytomegalovirus prophylaxis and natural killer cell count. A single-center cohort study. Transpl Int (2018) 31:187-97. doi:10.1111/ tri. 13076

21. Hamaguchi Y, Mori A, Uemura T, Ogawa K, Fujimoto Y, Okajima H, et al. Incidence and risk factors for herpes zoster in patients undergoing liver transplantation. Transpl Infect Dis (2015) 17:671-8. doi:10.1111/ tid. 12425

22. Manuel O, Kumar D, Singer LG, Cobos I, Humar A. Incidence and clinical characteristics of herpes zoster after lung transplantation. J Heart Lung Transplant (2008) 27:11-6. doi:10.1016/j.healun.2007.09.028

23. Fuks L, Shitrit D, Fox BD, Amital A, Raviv Y, Bakal I, et al. Herpes zoster after lung transplantation: incidence, timing, and outcome. Ann Thorac Surg (2009) 87:423-6. doi:10.1016/j.athoracsur.2008.11.004

24. van Besouw NM, van Hal PT, Zuijderwijk JM, de Kuiper R, Hoek RAS, van Weezel JJ, et al. Herpes zoster after lung transplantation boosts varicella zoster virus-specific adaptive immune responses. J Heart Lung Transplant (2016) 35:1435-42. doi:10.1016/j.healun.2016.04.009

25. Koo S, Gagne LS, Lee P, Pratibhu PP, James LM, Givertz MM, et al. Incidence and risk factors for herpes zoster following heart transplantation. Transpl Infect Dis (2014) 16:17-25. doi:10.1111/tid.12149

26. Pergam SA, Limaye AP; AST Infectious Diseases Community of Practice. Varicella zoster virus in solid organ transplantation. Am J Transplant (2013) 13:138-46. doi:10.1111/ajt.12107

27. Tunbridge AJ, Breuer J, Jeffery KJM. Chickenpox in adults - clinical management. J Infect (2008) 57:95-102. doi:10.1016/j.jinf.2008.03.004

28. Bader MS. Herpes zoster: diagnostic, therapeutic, and preventive approaches. Postgrad Med (2013) 125:78-91. doi:10.3810/pgm.2013.09.2703

29. Werner RN, Nikkels AF, Marinovic B, Schafer M, Czarnecka-Operacz M, Agius AM, et al. European consensus-based (S2k) guideline on the management of herpes zoster - guided by the European Dermatology Forum (EDF) in cooperation with the European Academy of Dermatology and Venereology (EADV), part 1: diagnosis. JEur Acad Dermatol Venereol (2017) 31:20-29. doi:10.1111/jdv.13995

30. Hong YJ, Lim MS, Hwang SM, Kim TS, Park KU, Song J, et al. Detection of herpes simplex and varicella-zoster virus in clinical specimens by multiplex real-time PCR and melting curve analysis. Biomed Res Int (2014) 2014:261947. doi:10.1155/2014/261947

31. Wong AA, Pabbaraju K, Wong S, Tellier R. Development of a multiplex realtime PCR for the simultaneous detection of herpes simplex and varicella zoster viruses in cerebrospinal fluid and lesion swab specimens. J Virol Methods (2016) 229:16-23. doi:10.1016/j.jviromet.2015.12.009

32. Wilson DA, Yen-Lieberman B, Schindler S, Asamoto K, Schold JD, Procop GW. Should varicella-zoster virus culture be eliminated? A comparison of direct 
immunofluorescence antigen detection, culture, and PCR, with a historical review. J Clin Microbiol (2012) 50:4120-2. doi:10.1128/JCM.06753-11

33. Heaton PR, Espy MJ, Binnicker MJ. Evaluation of 2 multiplex real-time PCR assays for the detection of HSV-1/2 and varicella zoster virus directly from clinical samples. Diagn Microbiol Infect Dis (2015) 81:169-70. doi:10.1016/j. diagmicrobio.2014.11.012

34. Tan TY, Zou H, Ong DCT, Ker KJ, Chio MTW, Teo RYL, et al. Development and clinical validation of a multiplex real-time PCR assay for herpes simplex and varicella zoster virus. Diagn Mol Pathol (2013) 22:245-8. doi:10.1097/ PDM.0b013e3182914291

35. Vizoso Pinto MG, Pfrepper K, Janke T, Noelting C, Sander M, Lueking A, et al. A systematic approach for the identification of novel, serologically reactive recombinant varicella-zoster virus (VZV) antigens. Virol J (2010) 7:165. doi:10.1186/1743-422X-7-165

36. Maple PA, Haedicke J, Quinlivan M, Steinberg SP, Gershon AA, Brown KE, et al. The differences in short- and long-term varicella-zoster virus (VZV) immunoglobulin $G$ levels following varicella vaccination of healthcare workers measured by VZV fluorescent-antibody-to-membrane-antigen assay (FAMA), VZV time-resolved fluorescence immunoassay and a VZV purified glycoprotein enzyme immunoassay. Epidemiol Infect (2016) 144:2345-53. doi:10.1017/S0950268816000595

37. De Paschale M, Clerici P. Microbiology laboratory and the management of mother-child varicella-zoster virus infection. World J Virol (2016) 5:97-124. doi:10.5501/wjv.v5.i3.97

38. Persson A, Bergström T, Lindh M, Namvar L, Studahl M. Varicella-zoster virus CNS disease - viral load, clinical manifestations and sequels. J Clin Virol (2009) 46:249-53. doi:10.1016/j.jcv.2009.07.014

39. Rondaan C, de Haan A, Horst G, Hempel JC, van Leer C, Bos NA, et al. Altered cellular and humoral immunity to varicella-zoster virus in patients with autoimmune diseases. Arthritis Rheumatol (2014) 66:3122-8. doi:10.1002/ art.38804

40. Werner RN, Nikkels AF, Marinovic B, Schafer M, Czarnecka-Operacz M, Agius AM, et al. European consensus-based (S2k) guideline on the management of herpes zoster - guided by the European Dermatology Forum (EDF) in cooperation with the European Academy of Dermatology and Venereology (EADV), part 2: treatment. J Eur Acad Dermatol Venereol (2017) 31:20-29. doi:10.1111/jdv.13957

41. De Clercq E, Field HJ. Antiviral prodrugs - the development of successful prodrug strategies for antiviral chemotherapy. Br JPharmacol (2006) 147:1-11. doi:10.1038/sj.bjp.0706446

42. Wilson JF. In the clinic. Herpes zoster. Ann Intern Med (2011) 154:15; quiz ITC316. doi:10.7326/0003-4819-154-5-201103010-01003

43. Styczynski J, Reusser P, Einsele H, de la Camara R, Cordonnier C, Ward KN, et al. Management of HSV, VZV and EBV infections in patients with hematological malignancies and after SCT: guidelines from the Second European Conference on Infections in Leukemia. Bone Marrow Transplant (2009) 43:757-70. doi:10.1038/bmt.2008.386

44. Sinko PJ, Balimane PV. Carrier-mediated intestinal absorption of valacyclovir, the L-valyl ester prodrug of acyclovir: 1 . Interactions with peptides, organic anions and organic cations in rats. Biopharm Drug Dispos (1998) 19:209-17. doi:10.1002/(SICI)1099-081X(199805)19:4<209::AID-BDD93>3.0. $\mathrm{CO} ; 2-\mathrm{O}$

45. Vigil KJ, Chemaly RF. Valacyclovir: approved and off-label uses for the treatment of herpes virus infections in immunocompetent and immunocompromised adults. Expert Opin Pharmacother (2010) 11:1901-13. doi:10.1517/14656566.2010.494179

46. Rajalakshmi R, Kumari R, Thappa DM. Acyclovir versus valacyclovir. Indian J Dermatol Venereol Leprol (2010) 76:439-44. doi:10.4103/0378-6323.66577

47. Tyring S, Belanger R, Bezwoda W, Ljungman P, Boon R, Saltzman RL. A randomized, double-blind trial of famciclovir versus acyclovir for the treatment of localized dermatomal herpes zoster in immunocompromised patients. Cancer Invest (2001) 19:13-22. doi:10.1081/CNV-100000070

48. Rabasseda X. Brivudine: a herpes virostatic with rapid antiviral activity and once-daily dosing. Drugs Today (2003) 39:359-71. doi:10.1358/dot. 2003.39.5.740221

49. Wutzler P, De Clercq E, Wutke K, Färber I. Oral brivudin vs. intravenous acyclovir in the treatment of herpes zoster in immunocompromised patients: a randomized double-blind trial. J Med Virol (1995) 46:252-7. doi:10.1002/ jmv. 1890460315
50. Piret J, Boivin G. Antiviral drug resistance in herpesviruses other than cytomegalovirus. Rev Med Virol (2014) 24:186-218. doi:10.1002/rmv.1787

51. Martin-GandulC, StampfS, Héquet D, Mueller NJ, Cusini A, van Delden C, et al. Preventive strategies against cytomegalovirus and incidence of $\alpha$-herpesvirus infections in solid organ transplant recipients: a Nationwide Cohort Study. Am J Transplant (2017) 17:1813-22. doi:10.1111/ ajt. 14192

52. Bacigalupo A, Boyd A, Slipper J, Curtis J, Clissold S. Foscarnet in the management of cytomegalovirus infections in hematopoietic stem cell transplant patients. Expert Rev Anti Infect Ther (2012) 10:1249-64. doi:10.1586/ eri.12.115

53. Ar MC, Ozbalak M, Tuzuner N, Bekoz H, Ozer O, Ugurlu K, et al. Severe bone marrow failure due to valganciclovir overdose after renal transplantation from cadaveric donors: four consecutive cases. Transplant Proc (2009) 41:1648-53. doi:10.1016/j.transproceed.2009.02.093

54. Billat P, Woillard J, Essig M, Sauvage F, Picard N, Alain S, et al. Plasma and intracellular exposure to ganciclovir in adult renal transplant recipients: is there an association with haematological toxicity? J Antimicrob Chemother (2016) 71:484-9. doi:10.1093/jac/dkv342

55. Massengill JS, Kittredge JL. Practical considerations in the pharmacological treatment of postherpetic neuralgia for the primary care provider. J Pain Res (2014) 7:125-32. doi:10.2147/JPR.S57242

56. Hadley GR, Gayle JA, Ripoll J, Jones MR, Argoff CE, Kaye RJ, et al. Post-herpetic neuralgia: a review. Curr Pain Headache Rep (2016) 20:17. doi:10.1007/s11916-016-0548-x

57. Attal N, Cruccu G, Baron R, Haanpää M, Hansson P, Jensen TS, et al. EFNS guidelines on the pharmacological treatment of neuropathic pain: 2010 revision. Eur J Neurol (2010) 17:e88. doi:10.1111/j.1468-1331.2010.02999.x

58. Baron R. Neuropathic pain: a clinical perspective. In: Canning BJ, Spina D, editors. Sensory Nerves. Berlin, Heidelberg: Springer Berlin Heidelberg (2009). p. 3-30.

59. Ogawa S, Satoh J, Arakawa A, Yoshiyama T, Suzuki M. Pregabalin treatment for peripheral neuropathic pain: a review of safety data from randomized controlled trials conducted in Japan and in the west. Drug Saf (2012) 35:793-806. doi:10.2165/11632660-000000000-00000

60. Meng FY, Zhang LC, Liu Y, Pan LH, Zhu M, Li CL, et al. Efficacy and safety of gabapentin for treatment of postherpetic neuralgia: a meta-analysis of randomized controlled trials. Minerva Anestesiol (2014) 80:556-67.

61. Pérez C, Navarro A, Saldaña MT, Masramón X, Rejas J. Pregabalin and gabapentin in matched patients with peripheral neuropathic pain in routine medical practice in a primary care setting: findings from a cost-consequences analysis in a nested case-control study. Clin Ther (2010) 32:1357-70. doi:10.1016/j.clinthera.2010.07.014

62. Ohishi A, Chisaki Y, Hira D, Nagasawa K, Terada T. Opioid analgesics increase incidence of somnolence and dizziness as adverse effects of pregabalin: a retrospective study. J Pharm Health Care Sci (2015) 1:30. doi:10.1186/ s40780-015-0032-5

63. Singh D, Kennedy DH. The use of gabapentin for the treatment of postherpetic neuralgia. Clin Ther (2003) 25:852-89. doi:10.1016/S0149-2918(03)80111-X

64. Baron R, Mayoral V, Leijon G, Binder A, Steigerwald I, Serpell M. 5\% Lidocaine medicated plaster versus pregabalin in post-herpetic neuralgia and diabetic polyneuropathy: an open-label, non-inferiority two-stage RCT study. Curr Med Res Opin (2009) 25:1663-76. doi:10.1185/03007990903047880

65. Wolff RF, Bala MM, Westwood M, Kessels AG, Kleijnen J. 5\% Lidocainemedicated plaster vs other relevant interventions and placebo for postherpetic neuralgia (PHN): a systematic review. Acta Neurol Scand (2011) 123:295-309. doi:10.1111/j.1600-0404.2010.01433.x

66. Ritchie M, Liedgens $\mathrm{H}$, Nuijten $\mathrm{M}$. Cost effectiveness of a lidocaine $5 \%$ medicated plaster compared with pregabalin for the treatment of postherpetic neuralgia in the UK: a Markov model analysis. Clin Drug Investig (2010) 30:71-87. doi:10.2165/11533310-000000000-00000

67. Navez ML, Monella C, Bösl I, Sommer D, Delorme C. 5\% lidocaine medicated plaster for the treatment of postherpetic neuralgia: a review of the clinical safety and tolerability. Pain Ther (2015) 4:1-15. doi:10.1007/ s40122-015-0034-x

68. Rehm S, Binder A, Baron R. Post-herpetic neuralgia: $5 \%$ lidocaine medicated plaster, pregabalin, or a combination of both? A randomized, open, clinical effectiveness study. Curr Med Res Opin (2010) 26:1607-19. doi:10.1185/ 03007995.2010.483675 
69. Harden RN, Kaye AD, Kintanar T, Argoff CE. Evidence-based guidance for the management of postherpetic neuralgia in primary care. Postgrad Med (2013) 125:191-202. doi:10.3810/pgm.2013.07.2690

70. Imoto K, Okazaki A, Onishi F, Miyazaki Y, Okeda M, Yano S, et al. VZV skin-test reaction, but not antibody, is an important predictive factor for postherpetic neuralgia. JDermatol Sci (2015) 79:235-40. doi:10.1016/j. jdermsci.2015.05.011

71. Johnson RW, Bouhassira D, Kassianos G, Leplège A, Schmader KE, Weinke T. The impact of herpes zoster and post-herpetic neuralgia on quality-of-life. BMC Med (2010) 8:37. doi:10.1186/1741-7015-8-37

72. Centers for Disease Control and Prevention (CDC). Update on herpes zoster vaccine: licensure for persons aged 50 through 59 years. MMWR Morb Mortal Wkly Rep (2011) 60:1528.

73. Dooling KL, Guo A, Patel M, Lee GM, Moore K, Belongia EA, et al. Recommendations of the Advisory Committee on Immunization Practices for use of herpes zoster vaccines. MMWR Morb Mortal Wkly Rep (2018) 67:103-8. doi:10.15585/mmwr.mm6703a5

74. Doan HQ, Ung B, Ramirez-Fort MK, Khan F, Tyring SK. Zostavax: a subcutaneous vaccine for the prevention of herpes zoster. Expert Opin Biol Ther (2013) 13:1467-77. doi:10.1517/14712598.2013.830101

75. Oxman MN, Levin MJ, Johnson GR, Schmader KE, Straus SE, Gelb LD, et al. A vaccine to prevent herpes zoster and postherpetic neuralgia in older adults. N Engl J Med (2005) 352:2271-84. doi:10.1056/NEJMoa051016

76. Oxman MN, Levin MJ; Shingles Prevention Study Group. Vaccination against herpes zoster and postherpetic neuralgia. J Infect Dis (2008) 197:S236. doi:10.1086/522159

77. Schmader KE, Oxman MN, Levin MJ, Johnson G, Zhang JH, Betts R, et al. Persistence of the efficacy of zoster vaccine in the Shingles Prevention Study and the Short-Term Persistence Substudy. Clin Infect Dis (2012) 55:1320-8. doi:10.1093/cid/cis638

78. Morrison VA, Johnson GR, Schmader KE, Levin MJ, Zhang JH, Looney DJ, et al. Long-term persistence of zoster vaccine efficacy. Clin Infect Dis (2015) 60:900-9. doi:10.1093/cid/ciu918

79. Levin MJ, Schmader KE, Pang L, Williams-Diaz A, Zerbe G, Canniff J, et al. Cellular and humoral responses to a second dose of herpes zoster vaccine administered 10 years after the first dose among older adults. J Infect Dis (2016) 213:14-22. doi:10.1093/infdis/jiv480

80. Kumar D. Immunizations following solid-organ transplantation. Curr Opin Infect Dis (2014) 27:329-35. doi:10.1097/QCO.0000000000000078

81. Harpaz R, Ortega-Sanchez IR, Seward JF. Prevention of herpes zoster: recommendations of the Advisory Committee on Immunization Practices (ACIP). MMWR Recomm Rep (2008) 57:4.

82. Naidus E, Damon L, Schwartz BS, Breed C, Liu C. Experience with use of $\operatorname{Zostavax}((\mathrm{R}))$ in patients with hematologic malignancy and hematopoietic cell transplant recipients. Am J Hematol (2012) 87:123-5. doi:10.1002/ ajh. 22196

83. Issa NC, Marty FM, Leblebjian H, Galar A, Shea MM, Antin JH, et al. Live attenuated varicella-zoster vaccine in hematopoietic stem cell transplantation recipients. Biol Blood Marrow Transplant (2014) 20:285-7. doi:10.1016/j.bbmt.2013.11.013

84. Pandit A, Leblebjian H, Hammond SP, Laubach JP, Richardson PG, Baden LR, et al. Safety of live-attenuated measles-mumps-rubella and herpes zoster vaccination in multiple myeloma patients on maintenance lenalidomide or bortezomib after autologous hematopoietic cell transplantation. Bone Marrow Transplant (2018). doi:10.1038/s41409-018-0112-x

85. Miller G, Schaefer H, Yoder S, Miller R, Winokur P, Kotloff K, et al. A randomized, placebo-controlled phase I trial of live, attenuated herpes zoster vaccine in subjects with end-stage renal disease immunized prior to renal transplantation. Transpl Infect Dis (2018) 20:e12874. doi:10.1111/tid.12874

86. Clark TG, Cassidy-Hanley D. Recombinant subunit vaccines: potentials and constraints. Dev Biol (Basel) (2005) 121:153-63.

87. Lal H, Cunningham AL, Godeaux O, Chlibek R, Diez-Domingo J, Hwang S, et al. Efficacy of an adjuvanted herpes zoster subunit vaccine in older adults. N Engl J Med (2015) 372:2087-96. doi:10.1056/NEJMoa1501184

88. Cunningham AL, Lal H, Kovac M, Chlibek R, Hwang S, Díez-Domingo J, et al. Efficacy of the herpes zoster subunit vaccine in adults 70 years of age or older. N Engl J Med (2016) 375:1019-32. doi:10.1056/NEJMoa1603800

89. Chlibek R, Pauksens K, Rombo L, van Rijckevorsel G, Richardus $\mathrm{JH}$, Plassmann G, et al. Long-term immunogenicity and safety of an investigational herpes zoster subunit vaccine in older adults. Vaccine (2016) 34:863-8. doi:10.1016/j.vaccine.2015.09.073

90. Le P, Rothberg MB. Cost-effectiveness of the adjuvanted herpes zoster subunit vaccine in older adults. JAMA Intern Med (2018) 178(2):248-58. doi:10.1001/jamainternmed.2017.7431

91. Stadtmauer EA, Sullivan KM, Marty FM, Dadwal SS, Papanicolaou GA, Shea TC, et al. A phase $1 / 2$ study of an adjuvanted varicella-zoster virus subunit vaccine in autologous hematopoietic cell transplant recipients. Blood (2014) 124:2921-9. doi:10.1182/blood-2014-04-573048

92. Cunningham AL, Heineman T. Vaccine profile of herpes zoster (HZ/su) subunit vaccine. Expert Rev Vaccines (2017) 16:1-10. doi:10.1080/14760584. 2017.1329012

93. Tomblyn M, Chiller T, Einsele H, Gress R, Sepkowitz K, Storek J, et al. Guidelines for preventing infectious complications among hematopoietic cell transplantation recipients: a global perspective. Biol Blood Marrow Transplant (2009) 15:1143-238. doi:10.1016/j.bbmt.2009.06.019

94. Seo H, Kim YS, Bang CH, Lee JH, Lee JY, Lee D, et al. Antiviral prophylaxis for preventing herpes zoster in hematopoietic stem cell transplant recipients: a systematic review and meta-analysis. Antiviral Res (2017) 140:106-15. doi:10.1016/j.antiviral.2017.01.011

95. Sahoo F, Hill JA, Xie H, Leisenring W, Yi J, Goyal S, et al. Herpes zoster in autologous hematopoietic cell transplant recipients in the era of acyclovir or valacyclovir prophylaxis and novel treatment and maintenance therapies. Biol Blood Marrow Transplant (2017) 23:505-11. doi:10.1016/j.bbmt.2016.12.620

96. Mao J, McPheeters JT, Zhang D, Acosta CJ, Finelli L. Herpes zoster incidence and cost in patients receiving autologous hematopoietic stem-cell transplant. Curr Med Res Opin (2018) 34:741-9. doi:10.1080/03007995.2017.1384374

97. Kawamura K, Hayakawa J, Akahoshi Y, Harada N, Nakano H, Kameda K, et al. Low-dose acyclovir prophylaxis for the prevention of herpes simplex virus and varicella zoster virus diseases after autologous hematopoietic stem cell transplantation. Int J Hematol (2015) 102:230-7. doi:10.1007/s12185-015-1810-4

98. Bapat P, Koren G. The role of VariZIG in pregnancy. Expert Rev Vaccines (2013) 12:1243-8. doi:10.1586/14760584.2013.844651

99. Centers for Disease Control and Prevention (CDC). Updated recommendations for use of VariZIG - United States, 2013. MMWR Morb Mortal Wkly Rep (2013) 62:574-6.

100. Jespersen C, Helmuth IG, Krause TG. Varicella-zoster immunoglobulin treatment in pregnant women in Denmark from 2005 to 2015: descriptive epidemiology and follow-up. Epidemiol Infect (2016) 144:3426-34. doi:10.1017/S0950268816001485

101. Rodriguez-Moreno A, Sanchez-Fructuoso AI, Calvo N, Ridao N, Conesa J, Marques $\mathrm{M}$, et al. Varicella infection in adult renal allograft recipients: experience at one center. Transplant Proc (2006) 38:2416-8. doi:10.1016/j. transproceed.2006.08.060

102. Prelog M, Schonlaub J, Zimmerhackl LB. Aciclovir and varicella-zosterimmunoglobulin in solid-organ transplant recipients. Pediatr Nephrol (2011) 26:663-73. doi:10.1007/s00467-010-1666-z

103. Troughton JA, Crealey G, Crawford V, Coyle PV. Management of varicella contacts in pregnancy: VZIG or vaccination? J Clin Virol (2009) 46:345-8. doi:10.1016/j.jcv.2009.09.014

104. Rommelaere M, Marechal C, Yombi JC, Goffin E, Kanaan N. Disseminated varicella zoster virus infection in adult renal transplant recipients: outcome and risk factors. Transplant Proc (2012) 44:2814-7. doi:10.1016/j. transproceed.2012.09.090

105. Zhang D, Johnson K, Newransky C, Acosta CJ. Herpes zoster vaccine coverage in older adults in the U.S., 2007-2013. Am J Prev Med (2017) 52:e23. doi:10.1016/j.amepre.2016.08.029

Conflict of Interest Statement: The authors declare that the research was conducted in the absence of any commercial or financial relationships that could be construed as a potential conflict of interest.

Copyright $\odot 2018$ Wang, Verschuuren, van Leer-Buter, Bakker, de Joode, Westra and Bos. This is an open-access article distributed under the terms of the Creative Commons Attribution License (CC BY). The use, distribution or reproduction in other forums is permitted, provided the original author $(s)$ and the copyright owner $(s)$ are credited and that the original publication in this journal is cited, in accordance with accepted academic practice. No use, distribution or reproduction is permitted which does not comply with these terms. 